\title{
Resposta do cafeeiro cv. Topázio MG-1190 submetido a diferentes épocas de irrigação'
}

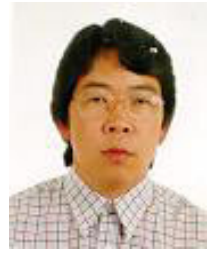

Shiguekazu Karasawa ${ }^{2}$, Manoel A. de Faria ${ }^{3}$ \& Rubens J. Guimarães ${ }^{4}$

1 Parte da Dissertação de Mestrado em Engenharia Agrícola, apresentada pelo primeiro autor à UFLA, projeto financiado por BIOEX-Café do CNPq

2 UFLA. Rua Samuel Neves 2307, Vila Independência, CP 37, CEP 13416-300, Piracicaba, SP. Fone: (19) $3402-9183$. E-mail: skarasaw@esalq.usp.br (Foto)

3 UFLA. CP 37, CEP 37200-000, Lavras, MG. Fone: (35) 3829-1390. E-mail: mafaria@ufla.br

${ }^{4}$ UFLA. Fone: (35) 3829-1311. E-mail: rubensjg@ufla.br

Protocolo $115-26 / 7 / 2001$

\begin{abstract}
Resumo: 0 presente trabalho foi desenvolvido na área experimental da Universidade Federal de Lavras, Lavras, MG, usando-se o cafeeiro da cultivar Topázio MG-1190, de 28 meses de idade, sistema de cultivo adensado com espaçamento de $1,80 \times 0,70 \mathrm{~m}$, irrigado por gotejamento, formando uma faixa molhada, com emissores de vazão de $4 \mathrm{~L} \mathrm{~h}^{-1}$, espaçados $40,0 \mathrm{~cm}$. Os tratamentos constaram de uma testemunha não irrigada e 5 diferentes épocas de irrigação: sem irrigação $\left(T_{0}\right)$; abril a julho $\left(T_{1}\right)$; abril a junho $\left(T_{2}\right)$; setembro a novembro $\left(T_{3}\right)$; maio a junho $\left(T_{4}\right)$; e agosto a outubro $\left(T_{5}\right)$, com irrigação nas terças e sextas-feiras. Para o manejo da irrigação utilizaram-se os dados de evaporação do tanque "Classe A" (ECA) em que a quantidade fornecida foi $83 \%$ da ECA. O delineamento utilizado foi de blocos casualizados, com 4 repetições, e os dados foram submetidos à análise de variância e teste de média Scott-Knott. Analisaram-se os ganhos nos parâmetros vegetativos, produtividade, qualidade e rendimento, de cada época da safra 99/00. Concluiu-se que: as irrigações, em diferentes épocas produziram efeitos apenas no ganho de altura e no diâmetro de copa, sem alterações na produtividade nem na qualidade do café produzido; as irrigações em diferentes épocas do ano não prejudicaram a qualidade do café produzido, nem mesmo no caso da irrigação realizada de setembro a novembro $\left(\mathrm{T}_{3}\right)$, que antecipou a maturação dos frutos, apresentando mais de $70 \%$ dos grãos no estádio passa e seco. 0 rendimento no beneficiamento do café também não foi influenciado pela época de irrigação, sendo que todos os tratamentos produziram café dentro dos padrões para exportação.
\end{abstract}

Palavras-chave: gotejamento, Coffea arabica L.

\section{Response of cv. Topázio MG-1190 coffee submitted to different periods of irrigation}

\begin{abstract}
This study was conducted in an experimental coffee (Topázio MG-1190) plantation at the Universidade Federal de Lavras, located in Lavras, in the state of Minas Gerais, Brazil. The 28-month-old experimental coffee plantation was established with a narrow spacing between plants $(1.8 \times 0.70 \mathrm{~m})$ and is drip irrigated. In July of 1998 , the installation of $4 \mathrm{~L} \mathrm{~h}^{-1}$ discharge emitters spaced at $0.40 \mathrm{~m}$ formed a wetted stripe along plant lines. The treatments were six different irrigation seasons: $T_{0}$ not irrigation, $T_{1}$ (irrigation from April to July), $T_{2}$ (irrigation from April to June), $T_{3}$ (irrigation from September to November), $T_{4}$ (irrigation from May to June), and $\mathrm{T}_{5}$ (irrigation from August to October). During the irrigation season an amount of water corresponding to $83 \%$ of the evaporation of a Class A pan was applied every Tuesday and Friday. The experimental design was a randomized complete block with four replications. The results were submitted to analysis of variance and to a Scott-Knott test of means. Vegetative growth, yield and yield quality from the 99/00 crop season were analyzed. Among all parameters used to quantify vegetative growth only stem diameter and plant height showed response to the treatments. The treatment $T_{3}$, in contrast to $T_{5}$, anticipated maturation, presenting more than $70 \%$ of grains at the raisin-grain and dry-grain stage. With respect to crop yield, neither the amount produced nor the percentage of coffee beans that fell on the soil before harvest showed significant differences between treatments. Both chemical and sensorial qualities were adequate, fulfilling the requirements for exportation.
\end{abstract}

Key words: drip irrigation, Coffea arabica L. 


\section{INTRODUÇÃO}

O cafeeiro necessita de alta disponibilidade de água no solo para o seu bom desenvolvimento, na maior parte do ciclo fenológico (Santinato et al. s/d). Como as chuvas geralmente se concentram no período de novembro a fevereiro, coincidindo com a fase de expansão dos grãos, nas demais fases a complementação de água por meio artificial se torna necessária.

Segundo Camargo (1987) nas condições da região Centro-sul, o déficit hídrico na fase de chumbinho (outubro a dezembro) atrasa o crescimento dos frutos e reduz a produtividade. O tamanho final do grão cereja depende acentuadamente da precipitação ocorrida no período de 10 a 17 semanas após o florescimento, período este considerado de expansão rápida do fruto. A expansão celular que delimita o tamanho do fruto, que ocorre nesta fase, é sensível ao déficit hídrico (Rena \& Maestri, 1987). Matiello et al. (1995) observaram, no sul de Minas Gerais e no Estado do Rio de Janeiro, no período de 1994/95, em cafeeiros das espécies arábica e canephora, o abortamento de botões florais antes de sua abertura, após chuvas insuficientes de 3 a $8 \mathrm{~mm}$, que provocaram o crescimento inicial dos botões, que não chegam a abrir, secando em seguida. De acordo com Batistela Sobrinho et al. (1985) o abortamento da florada, englobando botões florais não abertos, flores abertas e secas e formação de "estrelinhas", foi um fenômeno típico e marcante de déficit hídrico elevado, atingindo valores superiores a $50 \%$. Com a irrigação, diminui-se a porcentagem de flores "estrelinhas" de $57 \%$ a menos de $5 \%$ ou mesmo a $0 \%$ (Rena \& Maestri, 1987; Thomaziello, 1999).

$\mathrm{Na}$ fase de maturação e abotoação, de abril a junho, o déficit hídrico não afeta a maturação dos frutos já formados nem a produtividade do ano, porém prejudica a abotoação e a frutificação do ano seguinte; já na fase de dormência dos botões florais, de julho a setembro, a deficiência hídrica pode ser até benéfica, pelo fato de condicionar um florescimento abundante após chuvas ou irrigações, no final da fase, resultando numa frutificação e maturação uniformes na safra seguinte (Camargo, 1987).

Assim sendo, o objetivo do presente trabalho foi avaliar o crescimento, a produtividade, a qualidade de bebida e o rendimento do café submetido a diferentes épocas de irrigação, fora do período de chuva intensa, de novembro a fevereiro, visando economia de água, energia e mão-de-obra.

\section{MATERIAL E MÉTODOS}

\section{Caracterização do local e cultura}

O experimento foi conduzido na área experimental do setor de cafeicultura da Universidade Federal de Lavras (UFLA), município de Lavras, Minas Gerais, com latitude sul de $21^{\circ} 14^{\prime} 00^{\prime \prime}$, longitude oeste de $45^{\circ} 00^{\prime} 00^{\prime \prime}$ e altitude de $918 \mathrm{~m}$, numa lavoura cafeeira de 28 meses de idade, da cultivar Topázio MG-1190 (Coffea arabica L.), implantada no espaçamento de $1,80 \times 0,70 \mathrm{~m}\left(7936\right.$ plantas ha $\left.^{-1}\right)$ numa área total de 0,14 ha. $\mathrm{O}$ solo foi classificado como Latossolo Vermelho distroférrico, textura muito argilosa (EMBRAPA, 1999). Determinou-se a curva característica de retenção de água do solo e densidade aparente, nas camadas de 0-20, 20-40 e 40-60 cm, para obtenção da disponibilidade total de água e monitoramento do potencial matricial, conforme apresentado na Tabela 1.
Tabela 1. Resultados da caracterização físico-hídrica do solo usado no experimento, a partir dos dados obtidos em laboratório

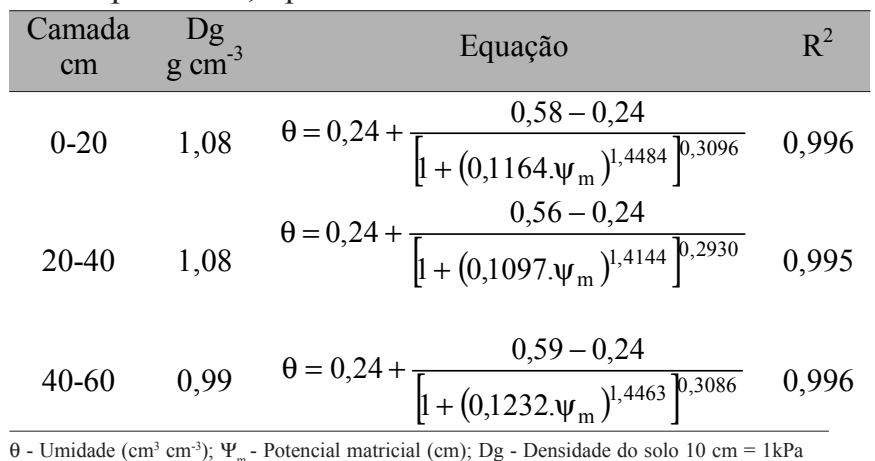

Delineamento experimental

O delineamento experimental foi o de blocos casualizados, com 6 tratamentos, constituindo 5 épocas de irrigação, além da testemunha e 4 repetições, assim identificados:

- $\mathrm{T}_{0}$ : sem irrigação

- $\mathrm{T}_{1}$ : irrigação de abril a julho

- $\mathrm{T}_{2}$ : irrigação de abril a junho

- $\mathrm{T}_{3}$ : irrigação de setembro a novembro

- $\mathrm{T}_{4}$ : irrigação de maio a junho

- $\mathrm{T}_{5}$ : irrigação de agosto a outubro

As parcelas constaram de 8 plantas, das quais as 6 centrais foram consideradas úteis.

Foram escolhidos diferentes períodos de irrigação entre abril a novembro, em razão de ser a época de pouca chuva na região em estudo, o que favorece a realização da colheita, porém a estiagem pode influenciar na produtividade e qualidade da safra seguinte. Entre os meses de abril a setembro acontece o desenvolvimento floral e nos meses de setembro a novembro ocorre o crescimento inicial dos frutos.

\section{Sistema de irrigação}

O sistema de irrigação usado foi por gotejamento, utilizando-se uma linha de gotejadores por fileira de plantas, com gotejadores de vazão nominal de $4 \mathrm{~L} \mathrm{~h}^{-1}$ espaçados $40 \mathrm{~cm}$ na linha, garantindo uma faixa molhada contínua.

O sistema de irrigação foi projetado para as condições do experimento e, após a instalação do mesmo no campo, foram novamente determinadas as curvas características (pressão $\mathrm{x}$ vazão) do conjunto motobomba e a uniformidade de emissão dos gotejadores, para maior garantia do controle da irrigação na forma prevista.

\section{Manejo da irrigação e adubação}

Cada tratamento teve a umidade do solo elevada à capacidade de campo, no início de sua respectiva época de irrigação. A determinação da umidade foi feita utilizando-se o método gravimétrico; já a lâmina de irrigação foi calculada em função de um coeficiente de cultura $(\mathrm{Kc})$ de 1,10, estimado em função do espaçamento, área foliar e da idade da lavoura. Como o manejo da irrigação foi baseado na evaporação do tanque "Classe A" e se considerando um coeficiente do tanque de 0,75 , obteve-se o coeficiente da estimativa da lâmina de irrigação igual a 0,83 , o que corresponde a $83 \%$ da evaporação do tanque. Por outro lado, a freqüência da irrigação adotada foi de 2 vezes 
por semana (nas terças e sextas-feiras) sendo que o cálculo da lâmina de irrigação foi feito através do balanço entre duas irrigações consecutivas da precipitação, medida em um pluviômetro localizado ao lado da área experimental e a evaporação do Tanque "Classe A" (ECA) localizado na estação meteorológica da UFLA, pertencente ao 5ํㅡㄴ Distrito de Meteorologia do INMET, distante aproximadamente $500 \mathrm{~m}$ do experimento.

Para a recomendação de adubação, utilizou-se o sistema modular (Malavolta \& Moreira, 1997) adotando-se 4 parcelamentos no período de outubro a março, feitos manualmente debaixo da copa do cafeeiro, alternando-se os lados de aplicação a cada adubação.

\section{Condução da lavoura}

O manejo da cultura foi o mesmo das lavouras tradicionais, ou seja, foram realizadas desbrotas, capinas manuais e químicas, controle de doenças e pragas e adubações foliares, com micronutrientes (boro, zinco e cobre). No controle da ferrugem foram utilizados o oxicloreto de cobre, junto com os micronutrientes boro e zinco, e o produto sistêmico Cyproconazole, em duas aplicações foliares (janeiro e março) na dosagem de $0,7 \mathrm{~L} \mathrm{ha}^{-1}$ a cada aplicação do produto comercial "Alto 100 ”. Para as quatro adubações foliares programadas utilizaram-se caldas com a seguinte composição: $0,6 \%$ de sulfato de zinco, 0,4\% de ácido bórico, $0,3 \%$ de oxicloreto de cobre, $0,25 \%$ de cloreto de potássio e $0,03 \%$ de espalhante adesivo (Santinato, 1997). As pulverizações foliares foram feitas com um pulverizador costal motorizado, aplicando-se em média $400 \mathrm{~L} \mathrm{ha}^{-1}$ de calda.

\section{Avaliações efetuadas}

As características vegetativas avaliadas, foram: altura da planta, diâmetro da copa, número de ramos plagiotrópicos, comprimento e número de nós nos ramos plagiotrópicos marcados, produtividade, rendimento, maturação, varrição e qualidade do café colhido.

Para a determinação da altura da planta foi empregada uma mira estadimétrica, com comprimento de $2 \mathrm{~m}$, medindo-se do colo da planta até o ponto de inserção da gema apical. $\mathrm{O}$ diâmetro de copa foi medido com uma trena graduada de $2 \mathrm{~m}$ na parte mediana da planta, tomando-se como referência os maiores ramos plagiotrópicos de ambos os lados da planta (na direção da entrelinha de plantas). A contagem do número de ramos plagiotrópicos foi realizada ao longo de todo o ramo ortotrópico e, para o comprimento dos seus ramos e número de nós, selecionaram-se quatro ramos plagiotrópicos por planta, previamente identificados, localizados no terço superior, com carga e direcionados para as entrelinhas. A medição dos ramos plagiotrópicos foi realizada com uma trena graduada, a partir das inserções dos mesmos até as suas extremidades.

Os dados analisados foram os incrementos obtidos no intervalo de um ano, contando-se do início de cada época em 1999 até o início da mesma época em 2000, para os tratamentos irrigados; para a testemunha os dados são os incrementos de junho de 1999 a junho de 2000.

Realizou-se a colheita em 19 de julho, manualmente, em pano próprio de colheita após o que se determinou o volume e o peso total da produção de cada parcela. Retirou-se uma amostra de $1 \mathrm{~L}$ para avaliação do grau de maturação, por meio de contagens de grãos de cada estádio de maturação (verde, verdecana, cereja, passa e seco) e, em seguida, a mesma foi retornada à origem, para se determinar o rendimento de café beneficiado e sua qualidade. Essas amostras foram acondicionadas em sacos perfurados que permitiam a circulação do ar e a incidência de luz; posteriormente, esses sacos foram expostos ao sol para secagem até a faixa de 11 a $12 \%$ de umidade, quando as amostras foram beneficiadas para as análises de qualidade da bebida (análises sensorial e química).

Para a análise sensorial adotou-se o processo usual da xícara, utilizando-se escala de valores segundo metodologia proposta por Garruti \& Conagin (1961); já na análise química, determinaram-se os compostos fenólicos totais e a atividade da enzima polifenoloxidase (PFO) conforme metodologias utilizadas por Chagas (1994).

\section{Análises estatísticas}

Com os dados obtidos, realizou-se a análise de variância e, quando esta foi significativa, aplicou-se o teste de média de Scott-Knott, em nível de significância de 5\% (Silva,1998).

Os dados, em porcentagem, foram transformados em arco seno da raiz do valor relativo, dividido por cem, e realizada a análise de variância para, em seguida, submetê-los ao teste de médias Scott-Knott.

\section{RESULTADOS E DISCUSSÃO}

\section{Crescimento e produtividade}

Apresenta-se, na Tabela 2, o resumo da análise de variância dos ganhos obtidos das características vegetativas e produtivas das épocas de irrigação. Nas Figuras 1A e B apresenta-se o efeito das épocas de irrigação sobre as características as quais foram significativas na análise de variância.

Tabela 2. Resumo da análise de variância dos incrementos obtidos em 365 d, para as características altura, diâmetro de copa (Dcopa), número de ramos plagiotrópicos (NRp), comprimento do ramo plagiotrópico identificado (RPc) e produção da safra 99/00, do cafeeiro (Coffea arabica L.) cultivar Topázio MG-1190

\begin{tabular}{lcccccc}
\hline \multirow{2}{*}{ FV } & GL & \multicolumn{4}{c}{ Quadrado Médio } \\
\cline { 3 - 7 } & & Altura & Dcopa & NRp & RPc & Safra 99/00 \\
\hline Bloco & 3 & $12,3333^{\mathrm{NS}}$ & $6,0860^{\mathrm{NS}}$ & $4,3021^{\mathrm{NS}}$ & $79,2423^{\mathrm{NS}}$ & $25,8561^{\mathrm{NS}}$ \\
Época & 5 & $83,6000^{*}$ & $1599,4653^{*}$ & $6,5476^{\mathrm{NS}}$ & $46,4181^{\mathrm{NS}}$ & $132,6343^{\mathrm{NS}}$ \\
Resíduo & 15 & 13,8000 & 30,9712 & 4,3935 & 33,1013 & 122,8149 \\
Total & 23 & & & & \\
\hline CV $(\%)$ & & 17,69 & 27,31 & 15,02 & 35,70 & \\
Média Geral & & 21,000 & 20,3804 & 13,9588 & 16,1171 & 11,76 \\
\hline
\end{tabular}

* Significativo em nível de 5\% de probabilidade; ${ }^{\text {Ns }}$ Não significativo 

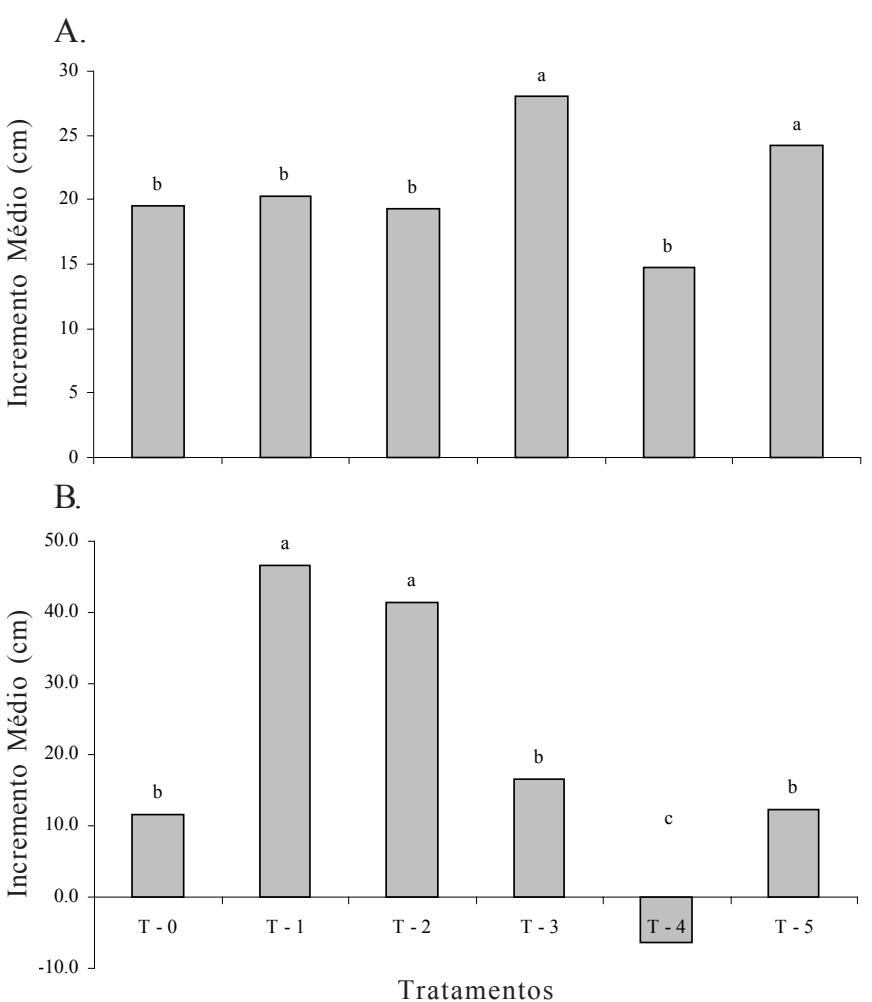

Figura 1. Efeito das épocas de irrigação sobre a altura (A) e o diâmetro de copa (B) do cafeeiro (Coffea arabica L.) cultivar Topázio MG-1190

Os resultados obtidos são de apenas um ciclo de irrigação, ou seja, 365 d, e somente os itens altura e diâmetro da copa foram significativos, enquanto as demais características não apresentaram diferença significativa nos diferentes tratamentos.

Observando-se a Figura 1A, verifica-se que a testemunha teve crescimento semelhante aos tratamentos $\mathrm{T}_{1}, \mathrm{~T}_{2}$ e $\mathrm{T}_{4}$, que, por sua vez, foram inferiores a $\mathrm{T}_{3}$ e $\mathrm{T}_{5}$. O pouco crescimento da $\mathrm{T}_{4}$ deve-se, possivelmente, ao fato da irrigação ter ocorrido somente no período de maio a junho, o qual coincide com período de menor temperatura (inverno) e, portanto, o desenvolvimento do cafeeiro é sensivelmente reduzido, chegando até mesmo à paralisação de crescimento da parte aérea. Como em julho a irrigação é interrompida, a parte desenvolvida nos meses anteriores com auxílio da irrigação acaba sendo muito pequena, ocasionando um descompasso na recuperação após a chegada do período chuvoso. O período de estiagem geralmente se estende até o mês de setembro, chegando até novembro em determinados anos. Por outro lado, os tratamentos que receberam irrigação no final da estação de inverno ao início de primavera, onde a temperatura média ambiental já está mais favorável para o desenvolvimento vegetativo do cafeeiro, porém ainda sem chuva, a irrigação pode complementar a necessidade hídrica, proporcionando uma antecipação no desenvolvimento, principalmente radicular, desses cafeeiros. Com a chegada das chuvas, os tratamentos que estavam recebendo irrigação complementar estão fisiologicamente em condições máximas para o desenvolvimento, quando comparadas com os de sequeiro ou irrigado apenas no início da época de seca. Assim, os tratamentos $\mathrm{T}_{3}$ e $\mathrm{T}_{5}$ apresentaram um crescimento mais intenso que os demais tratamentos, chegando a mais de $30 \%$ que a média e, quando comparados com a testemunha, o incremento de altura chegou a mais de $40 \%$.
Na Figura 1B, o diâmetro de copa da época $\mathrm{T}_{4}$ (maio a junho) apresentou redução no seu tamanho, devido à não recuperação vegetativa das extremidades dos ramos plagiotrópicos desidratados pelas adversidades climáticas ocorridas no período avaliado, provocando a seca de suas pontas e, por conseqüência, redução de tamanho. Como ocorreu morte de ponteiros e até de ramos, houve diminuição no tamanho da copa, em virtude da superprodução na safra 98/99 e da estiagem prolongada após esta safra. As parcelas de época $T_{4}$ foram as que receberam menor período de irrigação em relação às demais, sendo irrigados apenas nos meses de maio e junho, período este situado antes da colheita. Após a colheita, o cafeeiro sofreu danos e injúrias, devido à derriça que, somada à baixa umidade relativa e ao elevado déficit hídrico, provocou o depauperamento das plantas. Os tratamentos $\mathrm{T}_{1}$ e $\mathrm{T}_{2}$, praticamente não passaram por um período de estiagem após as chuvas, os quais terminaram em março, conforme pode ser visto na Figura 2. Como esses tratamentos continuaram recebendo complementação por mais 3 ou 4 meses, provavelmente possuem um sistema radicular mais desenvolvido que as épocas que receberam irrigação a partir do segundo semestre, o que permitiu ganho maior em relação aos demais tratamentos. Para o tratamento $T_{3}$, que recebeu complementação no meio do segundo semestre, obteve-se ganho inferior à metade das épocas $\mathrm{T}_{1} \mathrm{e}_{2}$ mas, comparando-o com o tratamento $T_{5}$, não apresentou diferença, pois o tempo de irrigação é o mesmo, ou seja, 3 meses.

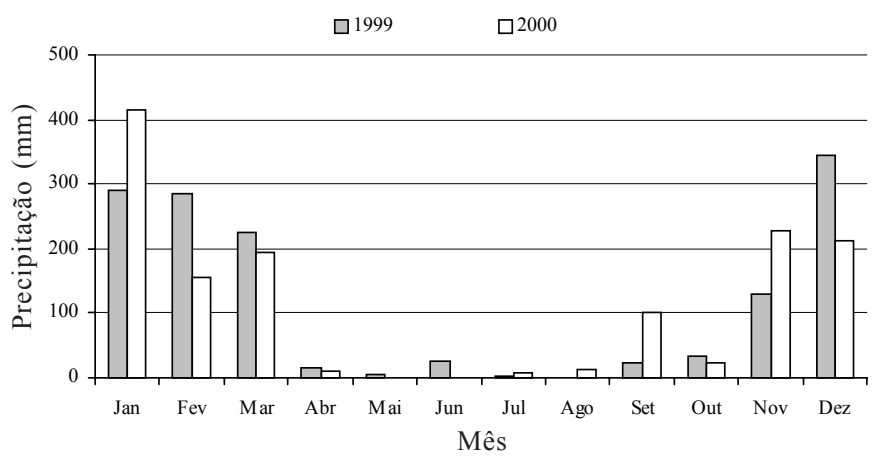

Figura 2. Total de precipitações mensais dos anos 1999 e 2000

Como citado, a variável crescimento do ramo plagiotrópico não obteve ganhos significativos em função de diferentes épocas de irrigação; Silveira \& Carvalho (1999) estudando a resposta da irrigação em diferentes épocas de irrigação no crescimento do ramo plagiotrópico do cafeeiro conilon, verificaram que a irrigação proporcionou, durante os meses mais secos, maior taxa de crescimento que o café não irrigado nesta época. Segundo esses autores, em lavouras irrigadas, durante o período seco, a primeira adubação do café deve ser antecipada para o mês de julho, pois a planta já se encontra em franco crescimento. Talvez esses resultados sejam explicados por se tratar da espécie Coffea canephora Pierre e de regiões com temperaturas elevadas.

Gervásio et al. (1999) verificaram, no cafeeiro (cultivar Topázio), que o maior crescimento ocorreu de setembro a março, quando as condições climáticas são mais favoráveis e, a partir daí, uma acentuada queda no crescimento, até o mês de junho. Após junho, houve retomada de crescimento para os tratamentos irrigados, não acontecendo o mesmo para o de 
sequeiro indicando, assim, uma possível antecipação das adubações nos tratamentos irrigados.

Observando-se a Figura 2, no ano de 1999, verifica-se que o período de estiagem foi de 7 meses, iniciando-se em abril e terminando em outubro. Os tratamentos das épocas $T_{1}$ e $T_{2}$ receberam irrigação no início do período de estiagem e, possivelmente, o sistema radicular desses se desenvolveu mais em relação às épocas $\mathrm{T}_{3}$ e $\mathrm{T}_{5}$, os quais receberam irrigação no final do período da estiagem, suportando a seca e desenvolvendo mais o diâmetro da copa.

Os tratamentos das épocas $\mathrm{T}_{3}$ e $\mathrm{T}_{5}$ receberam, para atingir a capacidade de campo no início do período de irrigação, 91,0 e $62,0 \mathrm{~mm}$ de lâmina de água, respectivamente. A recuperação desses tratamentos, mesmo o solo estando na capacidade de campo, é extremamente lenta, pois o microclima dentro da lavoura é pouco influenciado pelo sistema de irrigação utilizado. Nos meses de agosto e setembro, a umidade relativa do ar chegou perto de $35 \%$ e a temperatura máxima registrada foi acima de $30{ }^{\circ} \mathrm{C}$, por vários dias, causando grande evaporação, sendo que os valores desses meses ficaram na média de 5,5 $\mathrm{mm}$ diários, como pode ser constatado na Figura 3.



Figura 3. Média diária de evaporação do tanque Classe A nos diversos meses dos anos 1999 e 2000

A produtividade, apesar de não ter apresentado diferença significativa entre os tratamentos, devido provavelmente ao $\mathrm{CV}$, que foi muito elevado, 94,27\%, é interessante relatar que em algumas parcelas sem irrigação, não produziram nenhum grão e a média deste tratamento foi de 2,16 $\mathrm{sc} \mathrm{ha}^{-1}$; já para os tratamentos irrigados, todas as parcelas produziram, sendo que a média entre os tratamentos foi de 13,67 sc ha-1 e que o benefício da irrigação foi superior a $500 \%$ em relação aos tratamentos não irrigados.

\section{Rendimento e qualidade}

Para se obter uma saca de café beneficiado de $60 \mathrm{~kg}$ foram necessários, em média, $499 \mathrm{~L}$ de café da roça. $\mathrm{O}$ tratamento $\mathrm{T}_{3}$ apresentou rendimento de $430 \mathrm{~L}$ por saca de café beneficiado, e o tratamento $\mathrm{T}_{4}, 540 \mathrm{~L}$, porém não apresentaram diferença significativa, coincidindo com os resultados obtidos por Silva et al. (2000) que trabalharam com três períodos diferentes de irrigação em cafeeiro da cultivar Catuaí de 13 anos, no espaçamento de 3,50 x 1,00 m ( 2857 plantas ha-1).

$\mathrm{Na}$ Tabela 3 apresentam-se os resumos da análise de variância dos dados de maturação e, na Figura 4, tem-se a porcentagem de maturação, em função das épocas de irrigação. Observa-se que a maioria dos estádios de maturação foi influenciada, entre elas o verde, que é o estádio que merece especial atenção em razão, principalmente de se depreciar na qualidade, seguido de rendimento, porém se observou, nesse estádio, que o maior CV foi de 92,87\%. A irrigação nos meses de agosto a outubro foi favorável em relação ao incremento de altura, mas foi o tratamento que obteve maior porcentagem de grãos verdes no momento da colheita. Os tratamentos $\mathrm{T}_{3}$ e $\mathrm{T}_{4}$, juntamente com a testemunha, praticamente não tinham grãos verdes no momento da colheita. Os estádios verde-cana e passa não foram influenciados pela irrigação.

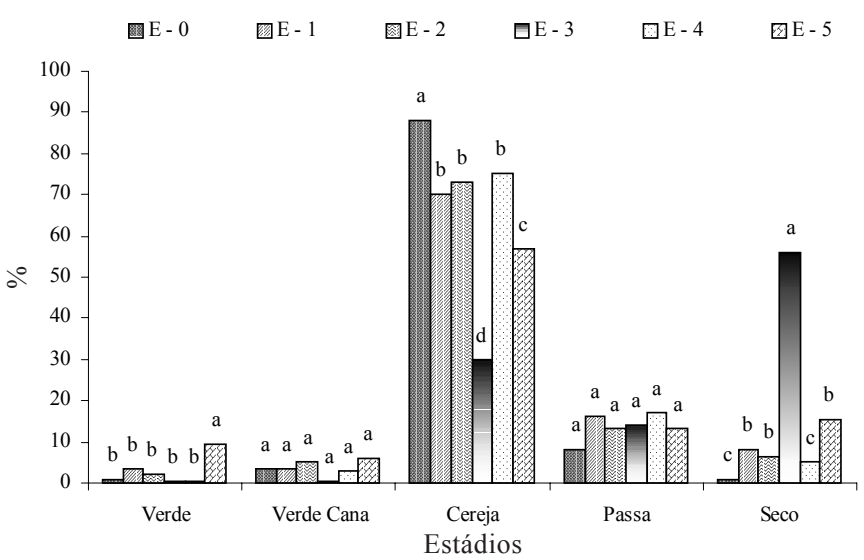

Figura 4. Grau de maturação em função das épocas de irrigação da safra $99 / 00$

Na época da colheita, a maior porcentagem de frutos estava no estádio cereja Figura 4, com média geral de $63 \%$ e a época $\mathrm{T}_{3}$ apresentou menor porcentagem de frutos cereja e maior porcentagem de frutos secos. Por outro lado, o cultivo convencional sem irrigação, $\mathrm{T}_{0}$ produziu, no total, $88 \%$ de café no estádio cereja, altamente favorável. Segundo Pimenta (1995) no estádio cereja os grãos se apresentam com maior rendimento e qualidade

Tabela 3. Resumo da análise de variância da porcentagem de cada estádio de maturação, em função das épocas de irrigação da safra 99/00, do cafeeiro cultivar Topázio MG-1190

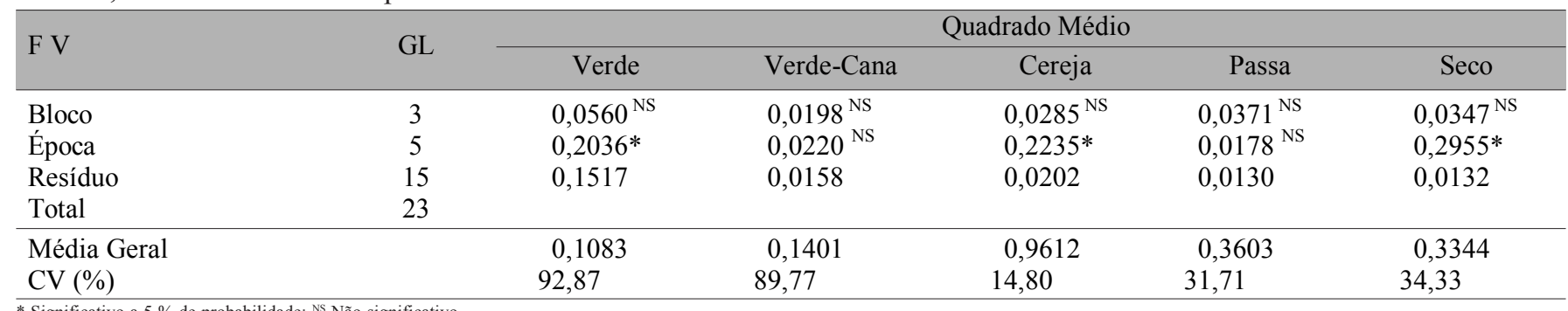


Tabela 4. Valores médios das variáveis analisadas nos grãos de café de cada época de irrigação, do cafeeiro (Coffea arabica L.) cultivar Topázio MG-1190

\begin{tabular}{ccccc}
\hline Tratamento & Fenólicos Totais $(\%)$ & PFO* & Classificação Química & Classificação Prova de Xícara \\
\hline $\mathrm{T}_{0}$ & 6,16 & 63,19 & Mole/A. Mole & A. Mole \\
$\mathrm{T}_{1}$ & 6,28 & 61,83 & Dura & Dura \\
$\mathrm{T}_{2}$ & 5,22 & 64,74 & Mole/A. Mole & A. Mole \\
$\mathrm{T}_{3}$ & 5,87 & 63,58 & Mole/A. Mole & A. Mole \\
$\mathrm{T}_{4}$ & 5,16 & 64,16 & Mole/A. Mole & A. Mole \\
$\mathrm{T}_{5}$ & 6,03 & 61,83 & Dura & A. Mole \\
\hline
\end{tabular}

* Polifenoloxidase: $\mathrm{u} \mathrm{min}^{-1} \mathrm{~g}^{-1}$ de amostra

de bebida máxima, considerado "Estritamente Mole"; portanto, deve-se realizar a colheita no momento em que a porcentagem de grãos verdes é mínima e o máximo de grãos está no estádio cereja. Observa-se que os tratamentos $\mathrm{T}_{1}, \mathrm{~T}_{2}$ e $\mathrm{T}_{4}$ não apresentaram diferença nos estádios de maturação de cereja, tendo todos apresentado valores próximos de $75 \%$; trata-se tratamentos nos quais o período de irrigação ocorreu antes da colheita do ano, com a finalidade de favorecer o desenvolvimento floral correspondente à colheita do ano seguinte. As épocas $T_{3}$ e $T_{5}$ são tratamentos que receberam irrigação após a colheita do ano e no início da florada relativa à colheita do ano seguinte. No tratamento $T_{3}$, a maturação foi adiantada e boa parte dos grãos no estádio cereja, na época em que foi realizada a colheita, já havia passado para estádio passa e seco. Ao contrário da época $T_{3}, a T_{5}$ apresentou boa proporção de grãos no estádio cereja, porém esses índices foram maiores para os estádios verde e verde-cana, caracterizando-se como época em que a maturação foi retardada, corroborando com Silva et al. (2000) que verificaram maior porcentagem de grãos verdes nas plantas que receberam irrigação a partir de julho.

Com relação à porcentagem de café de "varrição", realizouse análise estatística dos dados e o resultado obtido foi de que esses não apresentaram diferença.

Apresentam-se, na Tabela 4, os resultados dos valores médios das qualidades químicas e sensoriais, em função de diferentes épocas de irrigação.

$\mathrm{Na}$ Tabela 4, verifica-se que os tratamentos $\mathrm{T}_{1}$ e $\mathrm{T}_{5}$ foram os que apresentaram os maiores índices de porcentagem de grãos verdes na colheita (Figura 4) o que, provavelmente, comprometeu a qualidade, ficando como "Dura" na classificação química e de xícara. A qualidade de bebida dos cafés que receberam diferentes épocas de irrigação foi boa, visto que a maioria dos casos da prova de xícara apresentou a bebida "Apenas Mole", e tanto os fenólicos totais como a atividade de polifenoloxidase, oscilaram entre 6,28 a $5,16 \%$ e 61,83 a 64,74 u $\mathrm{min}^{-1} \mathrm{~g}^{-1}$ de amostra, respectivamente. A bebida "Apenas Mole", apresentada na maioria dos casos, é caracterizada por possuir sabor levemente suave, porém inferior à "Mole", que é de bebida de gosto agradável, brando e doce (Zambolim, 2000). Segundo este autor, a bebida "Dura" tem gosto acre, adstringente e áspero, mas sem paladares estranhos como, por exemplo, sabor típico de iodofórmio.

\section{CONCLUSÕES}

Nas condições em que foi realizado este experimento, conclui-se que:
1. Em diferentes épocas, as irrigações produziram efeitos apenas no ganho de altura e no diâmetro de copa.

2. As irrigações não produziram efeitos na produtividade nem na qualidade do café produzido.

3. Em diferentes épocas do ano, as irrigações não prejudicaram a qualidade do café produzido.

4. Realizada de setembro a novembro $\left(\mathrm{T}_{3}\right)$, a irrigação antecipou a maturação dos frutos, apresentando mais de $70 \%$ dos grãos no estádio passa e seco.

5. Na colheita, $95 \%$ dos grãos estavam no estádio cereja, e passa na parcela sem irrigação.

6. O rendimento no beneficiamento não foi influenciado pela época de irrigação.

7. A quantidade de café caído no chão antes da colheita foi estatisticamente igual para todos os tratamentos.

8. Todos os tratamentos produziram café dentro dos padrões para exportação.

\section{LITERATURA CITADA}

Batistela Sobrinho, I.; Miguel, A.E.; Matiello, J.B. Efeito da irrigação suplementar na estação seca no desenvolvimento e produção de café arábica na região de Alta Floresta, MT. In: Congresso Brasileiro de Pesquisas Cafeeiras, 12, 1985, Caxambú. Resumos... Caxambú: IBC, 1985. p.191-193.

Camargo, A.P. de. Balanço hídrico, florescimento e necessidade de água para o cafeeiro. In: Simpósio Sobre O Manejo de Água na Agricultura, 1987, Campinas. Anais... Campinas: Fundação Cargill, 1987. p.53-90.

Chagas, S.J. de Caracterização físico química e qualitativa de cafés de alguns municípios de três regiões produtoras de Minas Gerais. Lavras: UFLA, 1994. 83p.

EMBRAPA - Empresa Brasileira de Pesquisa Agropecuária Centro Nacional de Pesquisa de Solos (Rio de Janeiro, RJ). Sistema brasileiro de classificação de solos. Brasília: Embrapa Produção de Informação; Rio de Janeiro: Embrapa Solos, 1999. 412p.

Garruti, R.S.; Conagin, A. Escala de valores para avaliação da qualidade de bebida de café. Bragantia, Campinas, v.20, n.18, p.557-562, 1961 .

Gervásio, E.S.; Andrade Neto, A. de; Ferreira, M.A. Pezzo, A.M.; Faria, M.A. de.; Roque, M.W. Manejo da irrigação do cafeeiro na região sul de minas: perspectivas e viabilidades: relatório final BIOEX-CNPq, 1999.71p.

Malavolta, E.; Moreira, A. Nutrição e adubação do cafeeiro adensado. Informações Agronômicas, Piracicaba, n.80, 1997. Encarte Técnico, p.1-8 
Matiello, J.B.; Miguel, A.E.; Vieira, E.; Aranha, E. Novas observações sobre os efeitos hídricos no pegamento da florada de cafeeiros. In: Congresso Brasileiro de Pesquisas Cafeeiras, 21, 1995, Caxambú. Resumos... Caxambú: IBC, 1995. p.60.

Pimenta, C.J. Qualidade do café (Coffea arabica L.) originado de diferentes frutos colhidos em quatro estádios de maturação. Lavras: UFLA, 1995. 94p. Dissertação Mestrado

Rena, A.B.; Maestri, M. Ecofisiologia do cafeeiro. Piracicaba: Potafos, 1987. 249p.

Santinato, R. Gerenciamento da cultura cafeeira: curso: roteiro técnico e sugestões. Patrocínio: CACCER-PROCAFÉ, 1997. $34 \mathrm{p}$.

Santinato, R.; Fernandes, A.L.T.; Fernandes, D.R. Irrigação na cultura do café. snt. s/d. 146p.
Silva, A.M. da; Faria, M.A. de; Silva, P.A.M.; Coelho, G.; Castro, F.R. de; Coelho, M.R. Efeito da época de início da irrigação e do parcelamento de adubação sobre a uniformidade de maturação e produtividade do café. In: Simpósio de Pesquisa dos Cafés do Brasil, 1, 2000, Poços de Caldas. Resumos expandidos... Brasília: Embrapa Café, 2000. v.2, p.932-935.

Silva, E.C. da. Avaliação do poder e taxas de erro tipo I do teste de Scott-Knott por meio do método de Monte Carlo. Lavras: UFLA, 1998. 54p. Dissertação Mestrado

Silveira, J.S.M.; Carvalho, C.H.S. Efeito da época de irrigação sobre o crescimento, vingamento e maturação dos frutos do café conilon. In: Congresso Brasileiro De Pesquisas Cafeeiras, 29, 1999, Pelotas. Anais... Pelotas, 1999. CD-Rom

Thomaziello, R.A.; Oliveira, E.G. de; Toledo Filho, J.A de; Costa, T.E. da. Cultura do café. Campinas: CATI, 1999. 77p. CATI. Boletim Técnico, 193

Zambolim, L. Café: Produtividade, Qualidade e Sustentabilidade. Viçosa: UFV, 2000. 359p. 